\title{
Comparison of Outcomes between Clopidogrel and Ticagrelor in Patients Undergoing Primary Percutaneous Coronary Intervention in Acute Myocardial Infarction
}

\author{
Ranakishor Pelluri ${ }^{*}$, Thiruvaipati Sai Prasad ${ }^{2}$, Chandu Madhuri', Kommanaboina Supriya', \\ Kamma Sri Pandu Mukharjee', SYG Prasad', Rebba Sai Susmitha', Chinta Indu Radha', \\ Pydala Sai Prasanna', Puttagunta Srinivasababu' ${ }^{1}$
}

'Department of Pharmacy Practice, Vignan Pharmacy College, Vadalmudi, Guntur, Andhra Pradesh, INDIA.

${ }^{2}$ Department of Cardiology, Ramesh Hospitals, Guntur, Andhra Pradesh, INDIA.

\begin{abstract}
Background: Ticagrelor is more potent than clopidogrel, but it is not known whether this translates into clinical benefit is not well explored in patients undergoing primary Percutaneous coronary intervention (PCI) with aspirin for ST elevation myocardial infarction patients. Aim: To assess the improvement of therapeutic outcomes between clopidogrel and Ticagrelor in patients undergoing primary Percutaneous coronary intervention ( $\mathrm{PCl}$ ) in $\mathrm{AMI}$ patients. Methodology: It was a prospective observational study conducted at Ramesh hospital, Guntur, during the period of August 2017 to March 2018 (8 months). The study was approved from Institutional Human ethics committee. A 60 patients were enrolled with ACS with elapsed time between 12-24hrs of symptom onset. Before reperfusion therapy, they are treated with Aspirin, Clopidogrel/Ticagrelor before $\mathrm{PPCl}$ and after PPCl. Our study was aimed to safety and efficacy of anti-platelet drugs (Clopidogrel and Ticagrelor) after PPCI. Results: The clinical outcomes of our study TIMI grade-3 flow was observed in 4 patients $(13.33 \%)$ of clopidogrel group and 7 patients $(23.33 \%)$ in Ticagrelor group. The mean TIMI flow was observed in clopidogrel are 1.60 and 2.00 in Ticagrelor pretreated patients. Ticagrelor group patients had better TIMI flow than clopidogrel. The pumping capacity of the heart LVEF more than $50 \%$ was observed in Clopidogrel pretreated patients 8 (26.66) with the mean score of 1.0 and $>50 \%$ was observed in Ticagrelor pretreated patients $16(53.33 \%)$ with the mean score of 1.46. The mean score of ECG changes in clopidogrel were 0.50 and in Ticagrelor pretreated patients are 0.66 . There four there is no significant difference was observed in ST Segment resolution in Clopidogrel and Ticagrelor pretreated patients. The Regional Wall motion (abnormalities (RWMA) are observed that in Clopidogrel pretreated patients $9(30.00 \%)$ are with Hypokinetic with the mean score of 1.86 and in Ticagrelor pretreated patients $14(46.66 \%)$ with the mean score of 2.10 respectively. Therefore Ticagrelor shows more efficacious than Clopidogrel in all aspects, except ECG (ST segment resolution) changes. Conclusion: The findings in our study concludes that the Ticagrelor was more efficacious than clopidogrel and we are not observed any adverse drug reaction with both Ticagrelor and clopidogrel.
\end{abstract}

Key words: Clopidogrel, Ticagrelor, PPCl, Safety, Efficacy.
DOI: 10.5530/ijopp.12.1.3

Address for correspondence: Mr. Ranakishor Pelluri, Assistant Professor, Department of Pharmacy Practice, Vignan Pharmacy College, Vadalmudi, Guntur-522213 Andhra Pradesh, INDIA.

Phone no: +919032694102 Email Id: ranampharm@gmail. com

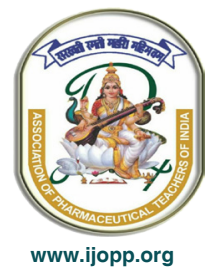

\section{INTRODUCTION}

Percutaneous coronary intervention (PCI), usually with stenting, has become the standard treatment for Acute coronary syndromes (ACS). During this procedure, trauma commonly occurs to the arterial endothelium that, among other effects, causes the activation and aggregation of platelets. Because platelet aggregation may lead to coronary thrombosis in a patient already vulnerable to it, Antiplatelet agents 
are essential adjunctive therapies in patients with ACS undergoing PCI. The goal of Antiplatelet therapy is to provide maximal protection against thrombosis without increasing the risk of bleeding. ${ }^{1}$ ST-segment elevation myocardial infarction (STEMI) accounts for approximately $30-45 \%$ of an estimated 1.5 million hospitalizations for acute coronary syndromes annually. ${ }^{2}$ Treatment includes drugs like aspirin, clopidogrel and ticagrelor. Thrombolysis in Myocardial Infarction (TIMI) grading system and Myocardial perfusion grade (MPG) are angiographic markers of efficacy of coronary reperfusion at the epicardial artery and microcirculation levels. ${ }^{3}$ The completeness of restoration of the epicardial blood flow after recanalization of infarct-related artery has been quantified with the Thrombolysis in Myocardial Infarction (TIMI) grading system. ${ }^{4}$ In most cases clopidogrel is used rather than ticagrelor so we concluded that clopidogrel is safest thanticagrelor.

\section{Aim}

To assess the improvement of therapeutic outcomes between clopidogrel and ticagrelor in patients undergoing primary Percutaneous coronary intervention (PCI) in AMI Patients

\section{Objectives}

- To evaluate Myocardial perfusion (TIMI grade flow) Score after PPCI.

- Assessment of RWMA (Regional Wall Motion Abnormality).

- To evaluate LV size Left ventricular ejection fraction $\%$ (LVEF) after PPCI.

- To assess the ECG changes after PPCI.

- To assess incidence of serious bleeding events and major adverse cardiovascular events after PPCI.

\section{METHODOLOGY}

It was a prospective observational study conducted at Ramesh hospital, Guntur, during the period of August 2017 to March 2018 (8 months), The study was approved from Institutional Human ethics committee. A 60 patients were enrolled with ACS with elapsed time between 12-24h of symptom onset, before reperfusion therapy, they are treated with crushed Aspirin $325 \mathrm{mg}$ P.O and Clopidogrel $600 \mathrm{mg}$ P.O /Ticagrelor $180 \mathrm{mg}$ P.O before PPCI and after PPCI. Our study was aimed to assess safety and efficacy of anti-platelet drugs (Clopidogrel and Ticagrelor) after PPCI.

\section{STUDY POPULATION}

\section{Inclusion Criteria}

Aged 19 to 70 years old, of either gender.

$>30 \mathrm{~min}$ or more persistent ischemia chest pain and symptoms can't ease by treated by nitroglycerin.

$>$ In two or more lead ECG ST-segment the line between QRS complex finish point and the start point of $\mathrm{T}$ wave in electrocardiogram) elevation $\geq$ $0.1 \mathrm{mv}$ or two or more than two neighboring chest lead ST-elevation $\geq 0.2 \mathrm{mv}$.

$>$ Persistent ischemia chest pain less than $9 \mathrm{~h}$ or less than $12 \mathrm{~h}$, door to balloon time $>90 \mathrm{~min}$ and transfer time $>120 \mathrm{~min}$.

$>$ Accept coronary arteriography and intervention treatment.

Signed informed consent.

\section{Exclusion Criteria}

$>$ Blood disease, clotting hemorrhagic disease, any part of active bleeding or bleeding tendency physique.

$>$ History of ischemic or hemorrhagic stroke and cerebrovascular accident.

$>$ History of PCI or coronary artery bypasses grafting (CABG)

$>$ History of eye ground hemorrhage.

$>$ Currently use of therapeutic doses of anticoagulants, such as warfarin, etc

> Active internal bleeding (such as gastrointestinal bleeding), urogenital system or have not cure of peptic ulcer in four weeks

$>$ Severe liver and kidney dysfunction

$>$ Intracranial tumor, suspicious aortic dissection, arteriovenous malformation, aneurysm.

\section{RESULTS AND DISCUSSION}

A total no of 60 patients 53 males $(88.33 \%)$ and 7 female $(11.62 \%)$ who have been admitted with AMI in intensive cardiac care unit, were monitored for efficacy and safety of pretreated anti-platelet therapy. The range of study population was 19-80 years (mean age \pm S.D was $65.27 \pm$ 9.333 years) BMI range was found to be 20 to $27 \mathrm{~kg} / \mathrm{m}^{2}$ (mean BMI \pm S.D $23.75 \pm 1.609 \mathrm{~kg} / \mathrm{m}^{2}$ ) the reperfusion therapy was performed $<12 \mathrm{~h}$ of onset of symptoms.

Table 1 shows that award of the score for different parameters in response to antiplatelet therapy with PCI. Table 2 shows that the distribution of 30 patients in both clopidogrel and ticagrelor group. 


\begin{tabular}{|c|c|c|}
\hline Parameters & Sub Parameters & $\begin{array}{c}\text { Score } \\
\text { awarded }\end{array}$ \\
\hline \multirow[t]{4}{*}{ TIMI $(0,1,2,3)$} & TIMI flow 0 & 0 \\
\hline & TIMI flow 1 & 1 \\
\hline & TIMI flow 2 & 2 \\
\hline & TIMI flow 3 & 3 \\
\hline \multirow[t]{2}{*}{ ECG Changes $(0,1)$} & ST segment-Resolution $>50 \%$ & 1 \\
\hline & ST segment- non resolution & 0 \\
\hline \multirow[t]{4}{*}{ RMWA $(0,1,2,3)}$, & Hypokinetic & 3 \\
\hline & Dyskinetic & 2 \\
\hline & Akinetic & 1 \\
\hline & Aneurysm & 0 \\
\hline \multirow[t]{2}{*}{ LV size } & Mild & 0 \\
\hline & Normal & 1 \\
\hline \multirow[t]{3}{*}{ LVEF\% $(0,1,2)$} & $<30 \%$ & 0 \\
\hline & $>40 \%$ & 1 \\
\hline & $>50 \%$ & 2 \\
\hline
\end{tabular}

\begin{tabular}{|c|c|}
\hline Anti-platelet drug used & No. of patients \\
\hline Clopidogrel & 30 \\
\hline Ticagrelor & 30 \\
\hline
\end{tabular}

The anti-platelet therapy given to the patients was described in Table 2 of 60 patients, $30(50 \%)$ patients were prescribed with Clopidogrel, 30 (50\%) Patients were prescribed with Ticagrelor.

Table 3 Shows the Clopidogrel treated patients are total 30 patients, among them 26 of male patients $(86.66 \%)$ there are very less number of female patients $4(13.3 \%)$. The Ticagrelor treated patients are a total 30 patients among them 27 of male patients $(90.00 \%)$ and there are very less number of female patients $3(10 \%)$. There are no patients of either gender in the age of $19-30$ years in both Clopidogrel and Ticagrelor patients. There are $50 \%$ of male patients with the range of age between $61-70$ years in each group.

Table 4 Shows descriptive details about the BMI, there are maximum number of overweight patients 21 $(70.00 \%)$ clopidogrel, $22(73.30 \%)$ in ticagrelor with a BMI of $23-25 \mathrm{~kg} / \mathrm{m}^{2}$. A few number with obeise in both groups 7 (23.30\%) with BMI of 26-30 kg $\backslash \mathrm{m}^{2}$. above characteristics shows that Overweight is one of the major contributing factor for development of ACS.

Table 5 Shows majority of patients 46 (76.66\%) underwent for reperfusion with DES among them 21 patients $(70.00 \%)$ of Clopidogrel pretreated group and 25
Table 3: Age and gender wise distribution in patients with AMI

\begin{tabular}{ccccc}
\multirow{2}{*}{$\begin{array}{c}\text { AGE } \\
\text { (years) }\end{array}$} & \multicolumn{2}{c}{ Clopidogrel } & \multicolumn{2}{c}{ Ticagrelor } \\
\cline { 2 - 5 } & Male $\boldsymbol{n}(\%)$ & $\begin{array}{c}\text { Female } \boldsymbol{n} \\
(\%)\end{array}$ & Male $\boldsymbol{n}(\%)$ & $\begin{array}{c}\text { Female } \boldsymbol{n} \\
(\%)\end{array}$ \\
\hline $19-30$ & $0(0.00)$ & $0(0.00)$ & $0(0.00)$ & $0(0.00)$ \\
$31-40$ & $1(3.33)$ & $0(0.00)$ & $0(0.00)$ & $0(0.00)$ \\
$41-50$ & $0(0.00)$ & $1(3.33)$ & $2(6.66)$ & $2(6.66)$ \\
$51-60$ & $2(6.66)$ & $1(3.33)$ & $2(6.66)$ & $0(0.00)$ \\
$61-70$ & $15(50.00)$ & $1(3.33)$ & $15(50.00)$ & $1(3.33)$ \\
$71-80$ & $8(26.66)$ & $1(3.33)$ & $8(26.66)$ & $0(0.00)$ \\
Total & $26(86.66)$ & $4(13.33)$ & 27 & 3 \\
Grand total & \multicolumn{2}{c}{30} & & 30 \\
\hline
\end{tabular}

\section{Table 4: BMI of study population}

\begin{tabular}{ccccc} 
SNO & BMI $\mathbf{k g} / \mathbf{m}^{2}$ & Category & $\begin{array}{c}\text { No. of } \\
\text { patients in } \\
\text { Clopidogrel } \\
\boldsymbol{n}=\mathbf{3 0}(\%)\end{array}$ & $\begin{array}{c}\text { No. of } \\
\text { patients in } \\
\text { Ticagrelor } \\
\boldsymbol{n}=\mathbf{3 0}(\%)\end{array}$ \\
\hline 1 & $18-22$ & $\begin{array}{c}\text { Normal } \\
\text { weight }\end{array}$ & $1(3.33)$ & $1(3.33)$ \\
2 & $23-25$ & Over weight & $21(70.00)$ & $22(73.33)$ \\
3 & $26-30$ & Obese & $7(23.30)$ & $7(23.30)$ \\
4 & $31-35$ & $\begin{array}{c}\text { Obese } \\
\text { grade -1 }\end{array}$ & $1(3.33)$ & $0(00.00)$ \\
\hline
\end{tabular}

Table 5: Type of stent used for Primary percutaneous coronary intervention

\begin{tabular}{ccc} 
Name of the stent & $\begin{array}{c}\text { Clopidogrel } \\
\boldsymbol{n}(\mathbf{\%})\end{array}$ & $\begin{array}{c}\text { Ticagrelor } \\
\boldsymbol{n}(\%)\end{array}$ \\
\hline BMS (Bare metal stent) & $9(30.00)$ & $5(16.66)$ \\
DES ( Drug eluting stent) & $21(70.00)$ & $25(83.30)$ \\
\hline
\end{tabular}

patients $(83.33 \%)$ of Ticagrelor pretreated group. There are less number of patients $14(23.33 \%)$ are underwent for reperfusion therapy with BMS, among them 9 patients $(30.00 \%)$ of Clopidogrel and $5(16.66 \%)$ of Ticagrelor group.

Table 6 Shows that the majority of patients $38(63.33 \%)$ have AWMI, among them $18(60.00 \%)$ in Clopidogrel treated patients and $20(33.33 \%)$ in Ticagrelor patients. There are less number of patients 19 (31.66\%) have IWMI, among them $9(30.00 \%)$ in Clopidogrel treated patients and $10(33.33 \%)$ in Ticagrelor patients there are $3(10.00 \%)$ Clopidogrel treated patients have PWMI and there are no PWMI patients in Ticagrelor group.

Table 7 Shows that the characteristics which include smoking history in $20(33.33 \%)$ patients, Alcoholism in 13 (21.66\%), Hyperlipidemic 20 (33.33\%), Diabetes mellitus $26(43.33 \%)$, hypertensive's $40(66.66 \%)$ and History of MI 15 (25.00\%) respectively.

Indian Journal of Pharmacy Practice, Vol 12, Issue 1, Jan-Mar, 2018 


\begin{tabular}{lcccc}
\hline Table 6: Localization of myocardial infarction \\
$\begin{array}{l}\text { Anti-platelet } \\
\text { drug }\end{array}$ & \multicolumn{4}{c}{ Localization of myocardial infraction } \\
\cline { 2 - 5 } & $\begin{array}{c}\text { (AWMI) } n \\
(\%)\end{array}$ & $\begin{array}{c}\text { (LWMI) } \boldsymbol{n} \\
(\%)\end{array}$ & $\begin{array}{c}\text { (IWMI) } \boldsymbol{n} \\
(\%)\end{array}$ & $\begin{array}{c}\text { (PWMI) } \boldsymbol{n} \\
(\%)\end{array}$ \\
\hline Clopidogrel & $18(60.00)$ & $0(0.00)$ & $9(33.00)$ & $3(10.00)$ \\
Ticagrelor & $20(33.33)$ & $0(0.00)$ & $10(16.66)$ & $0(0.00)$ \\
\hline
\end{tabular}

\begin{tabular}{cccc}
\hline \multicolumn{3}{l}{ Table 7: Base line characteristics } \\
Characteristics & \multicolumn{2}{c}{ Anti-platelet drugs used } & Total $\boldsymbol{n}(\%)$ \\
\cline { 2 - 3 } & $\begin{array}{c}\text { Clopidogrel } \\
\text { group }\end{array}$ & $\begin{array}{c}\text { Ticagrelor } \\
\text { group }\end{array}$ & \\
\hline Smoker & 15 & 5 & $20(33.33)$ \\
Alcoholism & 10 & 3 & $13(21.66)$ \\
Hyperlipidemia & 8 & 12 & $20(33.33)$ \\
Diabetes mellitus & 16 & 10 & $26(43.33)$ \\
Hypertensives & 20 & 20 & $40(66.66)$ \\
History of MI & 10 & 5 & $15(25.00)$ \\
\hline
\end{tabular}

Mortality after PPCI: In our study period we did not noticed mortality after PPCI.

From Table 8 overall efficacy parameters after PPCI shows that the Myocardial grade flow/ TIMI grade flow was found to be high in Ticagrelor (23.33) pretreated patients as compared with Clopidogrel (13.33), The mean score of Myocardial grade flow of Clopidogrel pretreated patients is 1.60 and Ticagrelor pretreated patients is 2.00 . The ECG Changes (ST - Segment resolution) was more in Ticagrelor treated patients 20 (66.66) compared to Clopidogrel treated patients 15 (50.00), the mean score of ECG Changes of Clopidogrel pretreated patients is 0.50 and Ticagrelor pretreated patients is 0.66 . The regional wall motion abnormalities with Hypokinetic patients in Ticagrelor is 14 (46.66) and clopidogrel treated patients with Hypokinetic in clopidogrel is 9 (30.00), the mean score of RWMA for Clopidogrel pretreated patients is 1.60 and Ticagrelor pretreated patients is 2.00 . The left ventricular hypertrophy is very less in Ticagrelor treated patients are 26 (86.66) compared to clopidogrel treated patients are 22 (73.33). The mean score of LV Size of

\begin{tabular}{|c|c|c|c|}
\hline SNO & PARAMETERS & $\begin{array}{l}\text { CLOPIDOGREL } \\
\text { GROUP } \boldsymbol{n}(\%)\end{array}$ & $\begin{array}{l}\text { TICAGRELOR } \\
\text { GROUP } \boldsymbol{n}(\%)\end{array}$ \\
\hline \multirow[t]{6}{*}{ I } & Myocardial grade flow / TIMI flow $(0,1,2,3)$ & & \\
\hline & I. a. TIMI flow - 0 & $00(0.00)$ & $00(0.00)$ \\
\hline & I. b. TIMI flow - 1 & $16(53.33)$ & $07(23.33)$ \\
\hline & I. c. TIMI flow - 2 & $10(33.33)$ & $16(53.33)$ \\
\hline & I. d. TIMI flow - 3 & $04(13.33)$ & $07(23.33)$ \\
\hline & lean Myocardial grade flow / TIMI flow & 1.60 & 2.00 \\
\hline \multirow[t]{4}{*}{ II } & ECG changes & & \\
\hline & II. a. Normal (ST-Segment resolution) & $15(50.00)$ & $20(66.66)$ \\
\hline & II. b. ST-Segment Non-resolution/ No change & $15(50.00)$ & $10(33.33)$ \\
\hline & Mean ECG Changes & 0.50 & 0.66 \\
\hline \multirow[t]{6}{*}{ III } & RWMA & & \\
\hline & III. a. Aneurysmal - 0 & $00(00.00)$ & $00(0.00)$ \\
\hline & III. b. Akinetic - 1 & $13(43.33)$ & $05(16.66)$ \\
\hline & III. c. Dyskinetic - 2 & $08(26.66)$ & $08(26.66)$ \\
\hline & III. d. Hypokinetic - 3 & $09(30.00)$ & $14(46.66)$ \\
\hline & an Regional Wall Motion Abnormalities & 1.86 & 2.10 \\
\hline \multirow[t]{4}{*}{ IV } & LV Size & & \\
\hline & IV. a. Mild - 0 & $08(26.66)$ & $04(13.33)$ \\
\hline & IV. b. Normal - 1 & $22(73.33)$ & $26(86.66)$ \\
\hline & Mean Left Ventricle Size & 0.73 & 0.86 \\
\hline \multirow[t]{5}{*}{ V } & LVEF\% & & \\
\hline & V. a. $<30 \%-0$ & $08(26.66)$ & $02(6.66)$ \\
\hline & V. b. $>40 \%-1$ & $14(46.66)$ & $12(40)$ \\
\hline & V. c. $>50 \%$ & $08(26.66)$ & $16(53.33)$ \\
\hline & Mean LVEF \% & 1.00 & 1.46 \\
\hline
\end{tabular}


Clopidogrel pretreated patients is 0.73 and Ticagrelor pretreated patients is $0.86 \mathrm{LVEF}>50 \%$ was observed in Ticagrelor treated patients are 16 (53.33) and Clopidogrel treated patients are 08 (26.66). The mean score of LVEF $\%$ in Clopidogrel pretreated patients is 1.00 and Ticagrelor pretreated patients is 1.46. The clinical outcomes of our study TIMI grade-3 flow was observed with mean score of 1.60 in Clopidogrel pretreated patients $4(13.33 \%)$ and in Ticagrelor pretreated patients $7(23.33 \%)$ with the mean score of 2.00 . The same results were observed in Eli-Lev Ran kornowski et al., ${ }^{(5)}$ they observed the potential benefit of pretreatment with Clopidogrel particularly TIMI -3 flow grade. Therefore pretreatment with a higher Clopidogrel dose may also improve TIMI flow at the end of procedure. The pumping capacity of the heart LVEF more than 50\% was observed in Clopidogrel pretreated patients 8 (26.66) with the mean score of 1.0 and $>50 \%$ was observed in Ticagrelor pretreated patients $16(53.33 \%)$ with the mean score of 1.46. Yumei Ye, Gilad D. Birnbaum et al., were observed that improved heart function in Ticagrelor pretreated patients. Therefore our study supports Ticagrelor shows improved heart function as compared with clopidogrel pretreated candidates undergoing PPCI. The mean score of ECG changes in clopidogrel were 0.50 and in Ticagrelor pretreated patients are 0.66. There four there is no significant difference was observed in ST Segment resolution in Clopidogrel and Ticagrelor pretreated patients. Lars Wallentin, Richard et al., ${ }^{7,8}$ observed Ticagrelor shows that better ST Segment resolution. The Regional Wall Motion Abnormalities (RWMA) are observed that in Clopidogrel pretreated patients 9 $(30.00 \%)$ are with Hypokinetic with the mean score of 1.86 and in Ticagrelor pretreated patients 14 (46.66\%) with the mean score of 2.10 respectively. Therefore Ticagrelor shows more efficacious than Clopidogrel in all aspects, except ECG (ST segment resolution) changes.

\section{CONCLUSION}

The finding in our study concludes that the Ticagrelor was more efficacious than clopidogrel in the clinical end poins of Myocardial grade flow, Regional wall motion abnormalities, left ventricular ejection fraction, left ventricular size and ST segment resolution. We are not observed any adverse drug reaction with both Ticagrelor and clopidogrel pretreated groups.

\section{LIMITATIONS OF THE STUDY}

In our study there are inadequate number of populations/ less sample size in group of patients. We did not conduct follow up after reperfusion therapy in PPCI patents, there four we are not noticed mortality and adverse drug reactions with anti-platelet drugs.

\section{ACKNOWLEDGEMENT}

We would like to express our gratitude to Department of Cardiology, Ramesh Hospital to providing opportunity to execute our research work.

\section{CONFLICT OF INTEREST}

The authors declare no conflict of interest.

\section{ABBREVIATIONS}

ACS: Acute Coronary Syndrome; AMI: Acute Myocardial Infarction; AWMI: Anterior wall Myocardial Infarction; PWMI: Posterior wall Myocardial Infarction; LWMI: Lateral wall Myocardial Infarction; IWMI: Inferior wall Myocardial Infarction; RWMI: Regional wall Myocardial Infarction; BMI: Body mass index; P.O: Oral; STEMI: ST segment elevated Myocardial Infarction; BMS: Bare metal stent; DES: Drug eluting stent; CABG: Coronary artery bypass graft; ECG: Electrocardiogram; PPCI: Primary Percutanious coronary intervention; TIMI: Thrombolysis in Myocardial Infarction; LVEF: Left ventriculr ejection fraction.

\section{REFERENCES}

1. Baigent C, Sudlow C, Collins R, Peto R. Antithrombotic Trialists' Collaboration. Collaborative meta-analysis of randomised trials of anti platelet therapy for prevention of death, myocardial infarction and stroke in high risk patients. BMJ. 2002;324(7329):71-86.

2. Lloyd J, Adams R, Carnethon M, et al. American Heart Association Statistics Committee and Stroke Statistics Sub-committee. Heart disease and stroke statistics-2009 Update: A report from the American Heart Association Statistics Committee and Stroke statistics Subcommittee. 2009;119:480-6.

3. Thygesen K, Alpert JS, Jaffe AS, et al. Third universal definition of myocardial infarction. Circulation. 2012;126:2020-35.

4. Balk EM, loannidis JP, Salem D, Chew PW, Lau J. Accuracy of biomarkers to diagnose acute cardiac ischemia in the emergency department: A metaanalysis. Ann Emerg Med. 2001;37(5):478-94.

5. Korff S, Katus HA, Giannitsis E. Differential diagnosis of elevated troponins. Heart. 2006;92(7):987-99

6. Montalescot G, Andersen HR, Antoniucci D, Betriu A, de Boer MJ, Grip L, et al. Recommendations on percutaneous coronary intervention for the reperfusion of acute ST elevation myocardial infarction. Heart. 2004;90(6):37-49.

7. Steinhubl SR, Berger PB, Mann JT, et al. Clopidogrel for the Reduction of Events during Observation. Early and sustained dual oral anti-platelet therapy following percutaneous coronary intervention: A randomized controlled trial. JAMA. 2002;288:2411-20.

8. Mohamed K, et al. Comparison of Clopidogrel with Prasugrel and Ticagrelor in Patients with Acute Coronary Syndrome: Clinical Outcomes from the National Cardiovascular Database action Registry. Cardiology Research. 2017;8(3):105. 